\title{
SINCRONIZAÇÃO DE ESTRO COM PROSTAGLANDINA F2 $\alpha$ versus PROGESTÁGENO ASSOCIADO À GONADOTROFINA CORIÔNICA EQUINA (eCG) EM OVELHAS SANTA INÊS NO DISTRITO FEDERAL, BRASIL
}

\author{
Bianca Damiani Marques Silva, ${ }^{1}$ Roberto Sartori, ${ }^{2}$ Thiago Antonio de Souza Nascimento Silva, ${ }^{3}$ \\ Déborah Mendes Máximo Cardozo, ${ }^{3}$ Marcos Antonio Lemos de Oliveira ${ }^{4}$ e \\ Jairo Pereira Neves 5 \\ 1. Mestranda em Ciência Animal pela FAV/UnB. E-mail: biancadamiani@yahoo. \\ 2. Pesquisador da EMBRAPA/CENARGEN \\ 3. FAV/UnB \\ 4. Professor doutor, UFRPE \\ 5. Professor doutor, FAV/UnB.
}

\section{RESUMO}

Este estudo teve por objetivo comparar o uso de um análogo da PGF2 $\alpha$ à associação de progestágeno (MAP) com gonadotrofina coriônica equina (eCG) na sincronização do estro em ovelhas da raça Santa Inês. Foram utilizadas 38 fêmeas ovinas submetidas a dois protocolos de sincronização de estro, com os seguintes protocolos: PGF $2 \alpha$ (duas doses de $0,53 \mathrm{mg}$ de D-cloprostenol com nove dias de intervalo) e protocolo $\mathrm{MAP}+\mathrm{eCG}$ (pessário intravaginal com $50 \mathrm{mg}$ de acetato de medroxiprogesterona por doze dias e no momento da remoção do dispositivo aplicação de 250 UI de eCG, IM). Submeteram-se as ovelhas aos diferentes protocolos, com intervalo de dois ciclos estrais. Procedeu-se a uma ultrassonografia transretal no último dia do protocolo, para avaliação do diâmetro do maior e do segundo maior folículo, e à coleta de sangue no dia sete do ciclo estral, para avaliação da concentração sérica de P4. Exame laparoscópico foi realizado no dia 11, após o fim dos protocolos, para contagem de corpos lúteos. Para os parâmetros taxa de sincronização, diâmetro do maior e do segundo maior folículo, período do final do protocolo ao estro e taxa de ovulação, não se observaram diferenças entre os mesmos. Foi observado que o protocolo MAP $+\mathrm{eCG}$ produziu concentrações séricas de P4 maiores do que o protocolo PGF2 $\alpha$ (3,9 e 2,8 ng/ $\mathrm{mL}$, respectivamente, $\mathrm{P}<0,05)$. Nas condições do presente estudo, embora o protocolo MAP+eCG tenha apresentado superioridade em relação à concentração sérica de $\mathrm{P} 4$, o protocolo $\mathrm{PGF} 2 \alpha$ foi tão eficiente quanto aquele em sincronizar o estro.

PALAVRAS-CHAVES: Diâmetro folicular, ovino, progesterona sérica, taxa de sincronização.

\section{ABSTRACT}

\section{ESTRUS SYNCHRONIZATION WITH PROSTAGLANDIN F2 $\alpha$ COMPARED TO PROGESTOGEN TREATMENT ASSOCIATED WITH EQUINE CHORIONIC GONADOTROPIN (eCG) IN SANTA INÊS BREED EWES REARED IN FEDERAL DISTRICT, BRAZIL}

The aim of this study was to compare two protocols of estrus synchronization in Santa Inês ewes. Thirty-eight ewes were randomly divided into two groups of estrus synchronization: protocol PGF $2 \alpha$ (two doses of $0.530 \mathrm{mg}$ of PGF $2 \alpha$, nine days apart) and protocol $\mathrm{MAP}+\mathrm{eCG}$ (intravaginal sponge impregnated with medroxyprogesterone acetate, for 12 days, and then an injection of $250 \mathrm{IU}$ of eCG). The experiment was in a cross-over design, two estrous cycles apart. On the final day of protocol, a transrectal ultrasound examination was carried out to measure the size of the largest and second largest ovarian follicles and on day 7 of estrous cycle blood was collected to measure serum P4 concentration. Laparoscopy was carried out on day 11 after the end of protocols 
to count corpora lutea. Synchronization rate, size of largest and second largest ovarian follicles, interval between the end of the protocol to estrus and ovulation rate did not differ between protocols. Ewes synchronized with $\mathrm{MAP}+\mathrm{eCG}$ had greater serum P4 concentrations than ewes synchronized with PGF2 $\alpha$ (3.9 and
$2.8 \mathrm{ng} / \mathrm{mL}$, respectively, $\mathrm{P}<0.05$ ). Based on the results, it may be concluded that, although the protocol $\mathrm{MAP}+\mathrm{eCG}$ was superior in inducing higher serum concentration of $\mathrm{P} 4$, the protocol PGF2 $\alpha$ was equivalent regarding estrus synchronization.

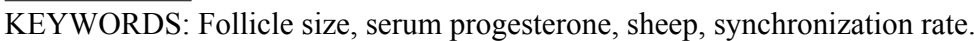

\section{INTRODUÇÃO}

A ovinocultura é uma atividade em crescimento, assinalando-se um incremento no número de cabeças na região Centro-Oeste (8.325 no ano de 2000 para 19.000 no ano de 2006), segundo dados do IBGE (2006). A atividade pecuarista está com interesse nessa espécie para criação, produção e consumo, principalmente porque as carnes ovinas oferecidas têm sido de animais novos e mediante cruzamentos industriais que proporcionam carne mais saborosa.

Das raças criadas no país, destaca-se a Santa Inês, uma raça deslanada, de grande porte, proveniente do Nordeste brasileiro e que se adapta facilmente a qualquer sistema de criação e pastagem. Além disso, possui uma boa conformação de carcaça e se destaca por ser bastante fértil, prolífica, precoce, rústica e resistente a parasitas gastrointestinais. Essa raça vem adquirindo grande importância na ovinocultura moderna, sendo utilizada tanto pura quanto para cruzamentos industriais.

A adaptabilidade da raça Santa Inês é uma característica relevante quando se trata de um país como o Brasil. Suas dimensões continentais e suas regiões, dadas as diversas características e climas diferentes, podem causar alterações na ciclicidade dos animais. Também a estacionalidade reprodutiva recebe muitas influências, tais como fotoperíodo, nutrição, idade, raça entre outras. Destaca-se que a escolha de raças adequadas às condições ambientais locais é um dos fatores preponderantes para o sucesso de um sistema de criação economicamente viável. Portanto, torna-se fundamental o estudo da raça Santa Inês na região do Distrito Federal, visando à obtenção de um maior conhecimento do rendimento dessa numa região de clima tropical, com verão úmido e chuvoso e um inverno seco e frio, ocasião em que a pastagem reduz drasticamente.

A sincronização de estro em ovinos é uma biotécnica reprodutiva que permite a concentração da inse- minação e da parição em épocas desejáveis dentro dos sistemas de produção (EVANS \& MAXWELL, 1987). Trata-se de técnica que tem sido utilizada em pequenos ruminantes, por meio do uso de esponjas intravaginais impregnadas com progestágenos, tais como acetato de fluorogestona (FGA) e acetato de medroxiprogesterona (MAP), prostaglandina F2 $\alpha$ (PGF2 $\alpha$ ), gonadotrofina coriônica equina (eCG), implante intravaginal de progesterona (P4; CIDR), consorciados ou não (DIAS et al., 2001).

O protocolo mais utilizado é a associação de P4 com eCG, que pode ser utilizado tanto na estação reprodutiva quanto fora dela, para estimular a ovulação (EVANS \& ROBINSON, 1980; EVANS \& MAXWELL, 1987; RUBIANES et al., 1998). Os protocolos desenvolvidos recomendam manter o dispositivo vaginal de P4 por períodos de doze a quatorze dias. Esses protocolos resultam em altas taxas de indução de estros nos animais tratados, porém com baixa fertilidade. Isso ocorre porque o tempo de manutenção do dispositivo gera um excessivo período de crescimento do folículo e, consequentemente, o envelhecimento do ovócito (VIÑOLES et al., 2001). Ademais, o uso excessivo de hormônios eCG pode provocar a produção de anticorpos anti-eCG, o que acarreta a diminuição da eficiência do tratamento hormonal (BARIL et al., 1996).

Como alternativa para a sincronização de estro, pode ser empregado um protocolo à base de PGF $2 \alpha$, que induz a regressão prematura do corpo lúteo por meio da interrupção da fase progestacional do ciclo estral, iniciando, assim, um novo ciclo (HERRERA et al., 1990). O protocolo, que utiliza duas doses de PGF2 $\alpha$, é uma alternativa ao produtor, para implementação da sincronização de estro na propriedade, como uma forma de aumentar a eficiência reprodutiva e proporcionar a redução nos custos com outros manejos, como sanitários, por concentrar os lotes com as mesmas exigências em um mesmo período e por reduzir os custos com mão de obra. 
No presente estudo objetivou-se comparar o protocolo de sincronização de estro à base de $\mathrm{PGF} 2 \alpha$ ao protocolo com MAP associada à eCG.

\section{MATERIAL E MÉTODOS}

O estudo foi realizado na Fazenda Água Limpa da UnB, situada em Brasília, DF, localizada a $15^{\circ} 46^{\prime}$ de latitude Sul e a $47^{\circ} 55^{\prime}$ de longitude Oeste a uma altitude de $1.171 \mathrm{~m}$, de clima tropical, no período de julho a outubro de 2007.

Utilizaram-se 38 fêmeas ovinas não gestantes e não lactantes da raça Santa Inês, examinadas quanto ao estado clínico geral, sanitário e reprodutivo, com um padrão de escore corporal entre 3 e 4, na escala de 1 a 5 (WHITE \& RUSSEL, 1984). As ovelhas foram inicialmente avaliadas quanto à ciclicidade estral e manifestação do estro mediante a utilização de um macho vasectomizado (rufião). Mantiveram-se os animais em sistema intensivo, recebendo água e sal mineral ad libidum e silagem de milho. Antes do início do experimento, os animais foram mantidos juntos por 45 dias, com o objetivo de proporcionar condições de adaptabilidade ambiental e o mesmo nível nutricional.

Em uma primeira etapa, dividiram-se os animais aleatoriamente em dois grupos, sendo submetidos a dois protocolos de sincronização (o primeiro dia do protocolo foi denominado D0). No protocolo PGF2 $\alpha$, aplicaram-se duas doses de PGF $2 \alpha \operatorname{IM}(0,530 \mathrm{mg}$ de D-cloprostenol, Ciosin; Schering-Plough, São Paulo) com intervalo de nove dias (D0 e D9) e no protocolo $\mathrm{MAP}+\mathrm{eCG}$ utilizaram-se pessários vaginais (BIOREP, UFSM, RS; D0) contendo $50 \mathrm{mg}$ de MAP inseridos na porção cranial da vagina por meio de um aplicador específico para fêmeas ovinas, permanecendo nela por doze dias. No momento da retirada dos pessários (D12), as ovelhas receberam 250 UI de eCG IM (Novormon; Schering-Plough, São Paulo). Ao fim do protocolo as ovelhas foram mantidas na presença de um macho vasectomizado, previamente testado, pintado com uma mistura de óleo e tinta em pó por todo o peito para marcação das fêmeas em estro. $\mathrm{O}$ macho vasectomizado permaneceu com as 38 fêmeas até a última manifestação de estro. As ovelhas foram observadas duas vezes ao dia (7:00 e 19:00 h) por um período de sessenta minutos em cada observação e consideradas em estro quando se observava o rufião montando e a fêmea permanecendo parada e/ou quando havia tinta na região da garupa da fêmea.

No D9 do protocolo PGF2 $\alpha$ e no D12 do protocolo MAP+ECG, avaliaram-se os ovários por ultrassonografia transretal com auxílio da técnica de laparoscopia. As ovelhas foram preparadas para laparoscopia, sendo mantidas previamente em jejum alimentar de 24 horas e hídrico de doze horas . Posteriormente, eram posicionadas em uma cama cirúrgica em decúbito dorsal, de modo a manter a cabeça inclinada para baixo e formando um ângulo de $45^{\circ}$. Procedeu-se à tricotomia e à antissepsia do abdômen, e nos locais onde foram inseridos os trocáteres, infiltraram-se $5,0 \mathrm{~mL}$ de lidocaína a 2,0\%. A cavidade abdominal foi distendida com dióxido de carbono, e com o laparoscópio (7,5 $\mathrm{mm}$ e $30^{\circ}$ Storz) visualizou-se o útero e fez-se apreensão dos ovários com pinça atraumática. Ao mesmo tempo, injetou-se carboximeticelulose com auxílio de uma seringa de $20 \mathrm{~mL}$ no reto, introduzindose um transdutor linear bifrequencial $(6,0$ e $8,0 \mathrm{MHz})$ do aparelho de ultrassom Falco 100 (Pie Medical, Nutricell, São Paulo). Acoplou-se o transdutor a um cano de pvc, para facilitar o seu manuseio no reto dos animais. As imagens foram obtidas na frequência de 8,0 MHz. Quando visualizadas, as imagens ovarianas eram congeladas, para a mensuração dos dois maiores folículos nos ovários.

Logo após o procedimento, retiraram-se o dióxido de carbono, por pressão abdominal, assim como o transdutor e os trocáteres. Os locais de punção receberam oxitetraciclina em forma de aerossol e pomada cicatrizante. As ovelhas foram retiradas da cama cirúrgica e encaminhadas a um piquete provido de água e alimento.

Após onze dias (D20, protocolo PGF2 $\alpha$ e D23, protocolo $\mathrm{MAP}+\mathrm{eCG}$ ) do final do protocolo, os animais foram submetidos à técnica de laparoscopia, conforme descrito anteriormente, para avaliação e contagem dos corpos lúteos.

Efetuaram-se coletas de sangue de todos os animais, para determinação sorológica da concentração de P4 sete dias após a observação do estro, sendo feitas por punção da veia jugular, em tubos a vácuo, os quais foram acondicionados a $5^{\circ} \mathrm{C}$ até a centrifugação, no dia seguinte à coleta. Logo após, o soro foi aspirado e estocado em tubos cônicos de $2,0 \mathrm{~mL}$ a $-20^{\circ} \mathrm{C}$ até a 
análise. Determinaram-se as concentrações séricas de $\mathrm{P} 4$ pela técnica de radioimunoensaio (RIA), por meio da utilização de kits comerciais (Coat-a-count, DPC, Diagnostic Products Co, Los Angeles, CA, USA) e seguindo as recomendações do fabricante. $\mathrm{O}$ coeficiente de variação intraensaio foi de $4,6 \%$, obtido em teste realizado no laboratório de Reprodução Animal da Embrapa Recursos Genéticos e Biotecnologia.

Para a segunda etapa, após um período de dois ciclos estrais, os animais foram ressincronizados, de modo a se alternar os tratamentos.

Testaram-se as variáveis analisadas quanto à sua normalidade e homocedasticia pelos testes de Lilliefors e Cochran, respectivamente. Procedeu-se à análise das variáveis que apresentaram distribuição normal e homocedasticia (concentração sérica de P4) pelo teste t pareado. Procedeu-se à análise das variáveis que não apresentaram distribuição normal pelo teste não paramétrico de Wilcoxon. As variáveis binomiais foram comparadas pelo teste Qui-quadrado. Para a discussão, utilizou-se o grau de significância de $\mathrm{P} \leq 0,05$.

\section{RESULTADOS E DISCUSSÃO}

Todas as ovelhas utilizadas no experimento foram detectadas em estro após a utilização de ambos os protocolos de sincronização (Tabela 1). No trabalho de MENCHACA et al. (2004), foi observado comportamento de estro dentro de 72 horas após a segunda dose de PGF $2 \alpha$ em 93,9\% das fêmeas multíparas e em $82,4 \%$ das nulíparas. GODFREY et al. (1997) observaram que, dentro de três dias, $71,4 \%$ das fêmeas entraram em estro após a segunda aplicação de PGF2 $\alpha$. RODRIGUES et al. (2004), estudando diferentes doses de eCG após a retirada do pessário vaginal em ovelhas deslanadas, observaram $100 \%$ de manifestação de estro nas ovelhas com dose de 200 UI de eCG. Resultado semelhante foi relatado por AINSWORTH \& WOLYNETZ (1982), em que se verificou estro em $96 \%$ das ovelhas tratadas com MAP+eCG. DIAS et al. (2001) obtiveram 76,7\% de ovelhas em estro após aplicação de 200 UI de eCG. Essa maior taxa de detecção de estro do presente estudo, em relação a alguns dos trabalhos citados, pode ser devida à introdução de um macho no mesmo dia do final dos protocolos, além da excelente condição corporal dos animais. Segundo YILDIZ et al. (2003), o estado nutricional das ovelhas também influencia a secreção de LH. As medidas de escore de condição corporal refletem o grau e armazenamento de energia do animal e estão relacionadas à eficiência reprodutiva, à taxa de mortalidade das crias e aos melhores resultados em programas de sincronização de estro.

Quando se trata do período de tempo entre o fim dos protocolos ao estro não houve diferença $(\mathrm{P}>0,05)$ entre os tratamentos PGF2 $\alpha$ e MAP + eCG (Tabela 1), apesar de GREYLING \& BRINK (1987) terem afirmado que o uso de eCG associado a progestágenos reduz o intervalo entre a remoção do implante ao estro. Além disso, EVANS \& ROBINSON (1980) observaram correlação negativa entre a dose de eCG utilizada e o tempo para manifestação de estro após o tratamento, com um decréscimo de 14 horas ao utilizar doses maiores (0-1600 UI de eCG). Esses mesmos autores, quando utilizaram 200 UI, observaram estro em ovelhas na contraestação com 48 horas do fim do tratamento. Nos estudos de GODFREY et al., (1997) verifica-se uma contradição em relação às horas até a manifestação do estro depois da segunda dose de PGF2 $\alpha$. Num primeiro trabalho, os autores observaram 69,6 horas (GODFREY et al., 1997), resultado similar aos obtidos no presente estudo, e num segundo trabalho observaram 31,6 horas (GODFREY et al., 1999), utilizando o mesmo protocolo. Esse contraste pode ser devido ao diferente estágio de desenvolvimento folicular em que as ovelhas se encontravam no momento do tratamento (VINÕLES \& RUBIANES, 1998).

MENCHACA et al. (2004), com aplicações de duas doses de análogos da PGF2 $\alpha$ dadas com sete dias de intervalo, observaram uma taxa de sincronização boa, com $80 \%$ das ovelhas com manifestação de estro entre 25 e 48 horas do tratamento. Essa manifestação de estro ocorreu mais cedo do que se pôde observar no presente estudo, entre 37 e 72 horas (Figura 1 e Tabela 2). Essa diferença de resultados entre os experimentos pode se dever, pelo menos parcialmente, ao intervalo de doze horas entre as observações de estro neste estudo e à não observação constante. 
TABELA 1. Manifestação de estro, período entre o final do protocolo ao estro, diâmetro do maior folículo e do segundo maior folículo, ovelhas com CL ao final do protocolo, média de folículos ovulados e concentração sérica de $\mathrm{P} 4$ no dia sete do ciclo estral nos protocolos de sincronização PGF2 $\alpha$ (duas injeções de PGF2 $\alpha$ com nove dias de intervalo, $\mathrm{n}=38$ ) e MAP $+\mathrm{eCG}$ (implante intravaginal de MAP mantido por doze dias e 250 UI de eCG foram aplicadas no momento da remoção do implante, $\mathrm{n}=38$ ) em ovelhas da raça Santa Inês (porcentagem ou média \pm EP)

\begin{tabular}{|c|c|c|}
\hline & PGF $2 \alpha$ & $\mathrm{MAP}+\mathrm{eCG}$ \\
\hline Ovelhas em estro; $\%(\mathrm{n} / \mathrm{n})$ & $100,0(38 / 38)$ & $100,0(38 / 38)$ \\
\hline $\begin{array}{l}\text { Tempo entre final do protocolo } \\
\text { ao estro; } h\end{array}$ & $66,0 \pm 2,5$ & $67,3 \pm 2,8$ \\
\hline Diâmetro do maior folículo; $\mathrm{mm}$ & $3,5 \pm 0,2$ & $3,1 \pm 0,2$ \\
\hline $\begin{array}{l}\text { Diâmetro do segundo maior folí- } \\
\text { culo; } \mathrm{mm}\end{array}$ & $2,4 \pm 0,2$ & $2,2 \pm 0,2$ \\
\hline $\begin{array}{l}\text { Ovelhas com CL no final do pro- } \\
\text { tocolo, } \%\end{array}$ & $79,0^{\mathrm{a}}$ & $7,9^{\mathrm{b}}$ \\
\hline Média de folículos ovulados; $\mathrm{n}$ & $1,5 \pm 0,1$ & $1,7 \pm 0,2$ \\
\hline Concentração sérica de $\mathrm{P} 4, \mathrm{n}$ & $2,8 \pm 0,1^{\mathrm{a}}$ & $3,9 \pm 0,1^{b}$ \\
\hline
\end{tabular}

${ }^{\mathrm{a}, \mathrm{b}}$ Diferença entre tratamentos $(\mathrm{P}<0,05)$.

Os resultados apresentados na Tabela 2 também demonstram uma tendência de um número maior de fêmeas que aceitam monta no período noturno (nos intervalos 37 a 48 horas e 61 a 72 horas). Há poucos relatos na literatura de observações desse tipo, ou seja, de um possível efeito de ritmo circadiano no comportamento estral.

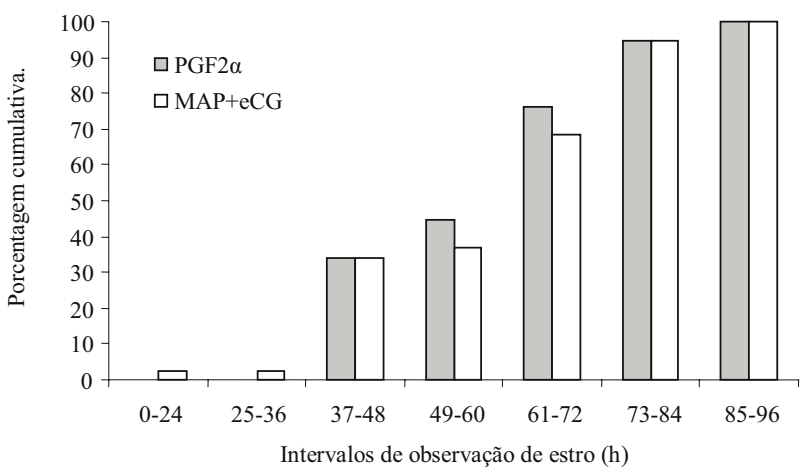

FIGURA 1. Dados acumulados de manifestação de estro nos intervalos de observação a cada doze horas a partir do final dos protocolos PGF2 $\alpha$ (duas injeções de PGF2 $\alpha$ com nove dias de intervalo, $\mathrm{n}=38$ ) e protocolo $\mathrm{MAP}+\mathrm{eCG}$ (implante intravaginal de P4 mantido por doze dias e $250 \mathrm{UI}$ de eCG aplicadas no momento da remoção do implante, $\mathrm{n}=38$ ), mostrando o agrupamento da manifestação de estro em cada intervalo até o fim da observação (porcentagem).

TABELA 2. Incidência de ovelhas marcadas pelo rufião no tratamento com PGF2 $\alpha$ (duas injeções de PGF2 $\alpha$ com nove dias de intervalo, $\mathrm{n}=38$ ) ou MAP+eCG (implante intravaginal de MAP mantido por doze dias e 250 UI de eCG aplicadas no momento da remoção do implante, $n=38$ ), nos intervalos de observação de estro a cada doze horas a partir do final dos protocolos (porcentagem)

\begin{tabular}{cccccccc}
\hline \multicolumn{7}{c}{ Intervalos de observação de estro (h) } \\
\hline & $0-24$ & $25-36$ & $37-48$ & $49-60$ & $61-72$ & $73-84$ & $85-96$ \\
\hline \multirow{2}{*}{ PGF2 $\alpha$; \% (n/n) } & 0 & 0 & 34,2 & 10,5 & 31,6 & 18,4 & 5,3 \\
& $(0 / 38)$ & $(0 / 38)$ & $(13 / 38)$ & $(4 / 38)$ & $(12 / 38)$ & $(7 / 38)$ & $(2 / 38)$ \\
\multirow{2}{*}{ P4+eCG; \% (n/n) } & 2,6 & 0 & 31,6 & 2,6 & 31,6 & 26,3 & 5,3 \\
& $(1 / 38)$ & $(0 / 38)$ & $(12 / 38)$ & $(1 / 38)$ & $(12 / 38)$ & $(10 / 38)$ & $(2 / 38)$ \\
\hline
\end{tabular}

A média do diâmetro do maior folículo e do segundo maior folículo observada ao exame ultrassonográfico ao fim do tratamento não diferiu entre os protocolos $(\mathrm{P}>0,05)$ (Tabela 1). CÁRDENAS et al. (2004) observaram folículos pré-ovulatórios de 7,6 mm após administração de PGF2 $\alpha$ e GnRH. LOPEZSEBASTIAN et al. (1997), avaliando a dinâmica folicular em ovelhas Merino, observaram os tamanhos dos dois maiores folículos nos ovários. O maior folículo permaneceu com tamanho constante nos últimos sete dias do ciclo estral (5,1 a 5,6 mm), mas aumentou para 6,6 mm no dia 0 (dia da manifestação de estro). Já o segundo maior folículo permaneceu com tamanho 3,9 mm. URIBE-VELÁSQUEZ et al. (2002) observaram diâmetro máximo de $4,3 \mathrm{~mm}$ do folículo, no dia da ovulação, para ovelhas tratadas com duas doses de PGF $2 \alpha$ com intervalo de nove dias e $5,4 \mathrm{~mm}$ para ovelhas tratadas com P4+eCG. Observaram também que o crescimento do folículo dominante nos animais tratados com $\mathrm{P} 4+\mathrm{eCG}$ foi maior que nos tratados com 
PGF2 $\alpha$, atribuindo esse resultado ao efeito da associação entre eCG e P4. Neste trabalho não foi observada diferença entre os protocolos, provavelmente porque as medições foram realizadas ao fim dos protocolos, não havendo tempo de ação da eCG. Diâmetros foliculares diferentes dos estudos citados anteriormente podem ter como causa o fato de os folículos terem sido medidos pelo menos dois dias antes de as ovelhas manifestarem estro. Nos outros estudos, eles foram medidos no dia da ovulação.

Ao exame ultrassonográfico realizado no último dia de tratamento hormonal dos protocolos, observouse que em $79,0 \%$ das ovelhas do grupo PGF2 $\alpha$ e em apenas $7,9 \%$ daquelas do grupo $\mathrm{P} 4+\mathrm{eCG}$ havia corpo lúteo presente em pelo menos um dos ovários. Esse resultado já era esperado, pois, em avaliação da dinâmica do protocolo MAP+ECG, a P4 permanece tempo o suficiente para haver luteólise (doze dias). Já o próprio princípio do protocolo PGF2 $\alpha$ baseia-se na presença de um corpo lúteo maduro no momento da segunda aplicação do medicamento, para que o programa de sincronização seja eficiente.

Independentemente do tratamento utilizado neste estudo, obteve-se uma alta taxa de folículos ovulados, em que $100 \%$ das ovelhas submetidas aos tratamentos com PGF $2 \alpha$ e com MAP + eCG ovularam pelo menos um folículo. Em análise da média de folículos ovulados entre os protocolos, não se verificou diferença entre o protocolo PGF2 $\alpha$ e o protocolo MAP $+\mathrm{eCG}$ (Tabela 1). Resultados semelhantes foram relatados por RODRIGUES et al. (2004) em ovelhas deslanadas, cuja taxa ovulatória foi de 1,4 $\pm 0,6$ com a dose 200 UI de eCG. Esses autores afirmaram que ovelhas deslanadas de clima tropical necessitam de doses menores para os trabalhos de sincronização de estro. Já DIAS et al. (2001) obtiveram 73,3\% de ovelhas com ovulação utilizando a mesma dose de 200 UI de eCG. No presente trabalho, não se observou diferença entre a média de folículos ovulados no ovário direito $(0,79)$ e no esquerdo $(0,78)$ em ambos os protocolos.

Para a concentração sérica de $\mathrm{P} 4$ no dia sete do ciclo estral, notou-se uma superioridade do protocolo $\mathrm{MAP}+\mathrm{eCG}$ em relação ao PGF2 $\alpha$ (Tabela 1). Esse resultado foi semelhante ao apresentado por URIBEVELÁSQUEZ et al. (2002) em ovelhas Bergamácia em que se utilizaram tratamentos com PGF2 $\alpha$ (aproximadamente, 4,0 $\mathrm{ng} / \mathrm{mL}$ ) e $\mathrm{P} 4+\mathrm{eCG}$ (aproximada- mente $6,0 \mathrm{ng} / \mathrm{mL}$ ). Resultado semelhante também foi apresentado por EVANS \& ROBINSON (1980), que obtiveram concentração de $\mathrm{P} 4$ no dia seis do ciclo estral de 3,3 $\pm 0,2 \mathrm{ng} / \mathrm{mL}$ após remoção do implante de $\mathrm{P} 4$ e aplicação de eCG.

EVANS \& ROBINSON (1980) demonstraram que a eCG pode superestimular os folículos ovarianos, resultando em corpos lúteos de maior diâmetro e consequentemente aumentando a concentração circulante de P4. Além disso, a eCG tem meia-vida prolongada (MAPLETOFT et al., 2002), promovendo um efeito estimulatório no corpo lúteo recém-formado. Concentração circulante elevada de $\mathrm{P} 4$ nos primeiros dias da fase luteal na ovelha é importante para a expressão de diversos fatores de crescimento, principalmente fatores de crescimento semelhantes à insulina (IGF), responsáveis pela implantação e crescimento fetal (OSGERBY et al., 1999), o que é crucial para o desenvolvimento embrionário. No entanto, com base nos resultados alcançados no presente estudo, não é possível afirmar que esse aumento de $\mathrm{P} 4$ circulante induzido pelo protocolo $\mathrm{MAP}+\mathrm{eCG}$ estaria correlacionado com maiores taxas de concepção, pois o experimento não foi delineado para testar essa hipótese.

Como ambos os protocolos foram eficientes em sincronizar o estro nas ovelhas do presente estudo, cria-se uma perspectiva atraente do uso em maior escala do protocolo PGF $2 \alpha$, por ser um protocolo de menor custo (entre $30 \%$ e $60 \%$ do custo em relação ao protocolo $\mathrm{MAP}+\mathrm{eCG}$ ). Apesar de haver estudos que mostram que o protocolo com PGF $2 \alpha$ pode afetar o transporte espermático e interferir na taxa de concepção (HAWK, 1973), há outros que mostram resultados satisfatórios e semelhantes, em comparação de protocolos com $\mathrm{P} 4$ versus PGF2 $\alpha$. GODFREY et al. (1997), por exemplo, não observaram diferença ( $100 \%$ e $86 \%$, respectivamente) na taxa de prenhez entre os tratamentos.

Este estudo foi realizado na contraestação reprodutiva (julho a outubro), nos meses em que não havia pastagem para os animais se alimentarem. Por isso foram mantidos em confinamento, o que pode ter contribuído com o fato de o fotoperíodo não ter interferido nos resultados. Caso contrário os animais não teriam respondido ao protocolo com PGF2 $\alpha$. Além disso, GODFREY et al. (1997) mostraram que o estro sincronizado com PGF2 $\alpha$ ou com P4 pode 
ser obtido com sucesso em ovelhas nos trópicos em diferentes épocas do ano. O fotoperíodo no local (Ilhas Virgens) flutua duas horas no ano e não parece ser o suficiente para influenciar a ciclicidade estral nas ovelhas. Apesar disso, estudo desenvolvido por MARTINS et al. (2003) mostrou que a qualidade seminal e, consequentemente, o diagnóstico de fertilidade foram afetados pelas variações estacionais, em carneiros da raça Santa Inês na região do Distrito Federal.

Apesar da eficácia, um fator negativo a ser considerado em relação ao protocolo MAP+eCG diz respeito ao fato de diversos países não permitirem mais a utilização de alguns tratamentos hormonais em animais de interesse zootécnico. Por exemplo, nos Estados Unidos, o "U.S. Food and Drug Administration" não aprova o uso do protocolo mencionado, o que limitou drasticamente o uso de tal tecnologia (CLINE et al., 2001). Além disso, um tratamento longo com progestágeno está relacionado a uma menor renovação folicular, promovendo a ovulação de folículos dominantes persistentes e gerando uma menor taxa de prenhez (VIÑOLES et al., 2001). A fertilidade pode ser reduzida também pelo uso repetido do tratamento com eCG para sincronizar o estro pelo crescimento de anticorpos anti-eCG (BARIL et al., 1996).

\section{CONCLUSÃO}

Nas condições do presente estudo, embora o protocolo $\mathrm{MAP}+\mathrm{eCG}$ tenha se apresentado superior, por ter aumentado a concentração sérica de $\mathrm{P} 4$, o protocolo PGF2 $\alpha$ foi tão eficiente em sincronizar o estro quanto aquele. Além de ter um custo menor, não apresenta problemas relacionados à superutilização da MAP e do eCG. Assim, ressalta-se o uso do protocolo alternativo com PGF2 $\alpha$.

\section{AGRADECIMENTOS}

Ao Conselho Nacional de Desenvolvimento Científico e Tecnológico (CNPq), pelo apoio financeiro, ao pesquisador Dr. Maurício Machaim Franco, pelo auxílio na análise estatística, à Dra. Concepta McManus e a Rogério Tokarski, pelo fornecimento dos animais.

\section{REFERÊNCIAS}

AINSWORTH, L.; WOLYNETZ, M. S. Synchronization of estrus and reproductive performance of ewes treated with synthetic progestagens administered by subcutaneous ear implant or by intravaginal sponge pessary. Journal of Animal Science, v. 54, n. 6, p. $1120-1127,1982$.

BARIL, G.; REMY, B.; LEBOEUF, B.; BECKERS, J. F.; SAUMANDE, J. Synchronization of estrus in goats: the relationship between eCG binding in plasma, time of occurrence of estrus and fertility following artificial insemination, Theriogenology, v. 45, p. $1553-1559,1996$.

CÁRDENAS, H.; WILEY, T. M.; POPE, W. F. Prostaglandin F2 $\alpha$ - induced estrus in ewes exhibiting estrous cycles of different duration. Theriogenology, v. 62, p. 123-129, 2004.

CLINE, M. A.; RALSTON, J. N.; SEALS, R. C.; LEWIS, G. S. Intervals from norgestomet withdrawal and injection of equine chorionic gonadotropin or P.G. 600 to estrus and ovulation in ewes, Journal of Animal Science, v. 79, p. 589-594, 2001.

DIAS, F. E. F.; JUNIOR, E. S. L.; VILLAROEL, A. B. S.; RONDINA, D.; FREITAS, V. J. F. Sincronização do estro, indução da ovulação e fertilidade de ovelhas deslanadas após tratamento hormonal com gonadotrofina coriônica equina. Arquivo Brasileiro Medicina Veterinária e Zootecnia, v. 53, n. 5, p. 618-623, 2001.

EVANS, G.; MAXWELL, W. M. C. Salamon's artificial insemination of sheep and goats. Sydney: Butterworths, 1987. 194 p.

EVANS, G.; ROBINSON, T. J. The control of fertility in sheep: endocrine and ovarian responses to progestagen-PMSG treatment in the breeding season and in anoestrus, Journal of Agricultural Science, v. 94, p. 69-88, 1980.

GODFREY, R. W.; GRAY, M. L.; COLLINS, J. R. A comparison of two methods of oestrous synchronization of hair sheep in the tropics, Animal Reproduction Science, v. 47, p. 99-106, 1997.

GODFREY, R. W.; COLLINS, J. R.; HENSLEY, E. L.; WHEATON, J. E. Estrus synchronization and artificial insemination of hair sheep ewes in the tropics. Theriogenology, v. 51, p. 985-997, 1999.

GREYLING, J. P. C.; BRINK, W. C. J. Synchronization of oestrus in sheep: the use of controlled internal drug release (CIDR) dispensers. South Afrikan Tydskr Veekderman, v. 17, p. 128$132,1987$.

HAWK, H. W. Uterine motility and sperm transport in the estrous ewe after prostaglandin induced regression of corpora lutea. Journal of Animal Science, v. 37, n. 6, p. 1380-1385, 1973. 
HERRERA, H. L.; FELDMAN, S. D.; ZARCO, Q. L. Evaluacion del efecto luteolítico de la prostaglandina $\mathrm{F}_{2} \alpha$ em diferentes días del ciclo estral de la borrega. Veterinaria México, v. 21, p. 143-147, 1990.

LOPEZ-SEBASTIAN, A.; GONZALEZ-BULNES, A. G.; MORENO, J. S.; GOMEZ-BRUNET, A.; TOWNSEND, E. C.; INSKEEP, E. K. Patterns of follicular development during the estrous cycle in monovular Merino del Pais ewes. Animal Reproduction Science, v. 48, p. 279-291, 1997.

MAPLETOFT, R. J.; STEWARD, K. B.; ADAMS, G. P. Recent advances in the superovulation in cattle. Reproduction, Nutrition, and Development, v. 42, p. 601-611, 2002.

MARTINS, R. D.; McMANUS, C.; CARVALHÊDO, A. S.; BORGES, H. V.; SILVA, A. E. D. F.; SANTOS, N. R. Avaliação da sazonalidade reprodutiva de carneiros Santa Inês criados no Distrito Federal. Revista Brasileira de Zootecnia, v. 32, p. 15941603, 2003.

MENCHACA, A.; MILLER, V.; GIL, J.; LACA, M.; RUBIANES, E. Prostaglandin F2 $\alpha$ treatment associated with timed artificial insemination in ewes. Reproduction Domestic Animal, v. 39, p. 352-355, 2004.

OSGERBY, J. C.; GADD, T. S.; WATHES, D. C. Expression of insulin-like growth factor binding protein-1 (IGFBP-1) mRNA in the ovine uterus throughout the oestrous cycle and early pregnancy. Journal of Endocrinology, v. 87, p. 162-279, 1999.

RODRIGUES, L. F. S.; ARAUJO, A. A.; NUNES, J. F.; MOURA, A. A. A.; MOREIRA, E. P. Sincronização do estro em ovelhas deslanadas: efeito de diferentes doses de gonadotrofina coriônica equina sobre a taxa de ovulação. Revista Ciências Agrárias, v. 41, p. 215-222, 2004.

RUBIANES, E.; CASTRO, T.; KMAID, S. Estrus response after a short progesterone priming in seasonally anestrous goats. Theriogenology, v. 49, p. 356-362, 1998.

URIBE-VELÁSQUEZ, L. F.; OBA, E.; LARA-HERRERA, L. C.; SOUZA, M. I. L; VILLA-VELÁSQUEZ, H.; TRINCA, L. A.; FERNANDES, C. A. C. Respostas endócrinas e ovarianas associadas com o folículo dominante da primeira onda folicular em ovelhas sincronizadas com CIDR ou PGF2 $\alpha$. Revista Brasileira de Zootecnia, v. 31, n. 2, p. 944-953, 2002.

VIÑOLES, C.; FORSBERG, M.; BANCHERO, G.; RUBIANES, E. Effect of long-term and short-term progestagen treatment on follicular development and pregnancy rate in cyclic ewes. Theriogenology, v. 55, p. 993-1004, 2001.

VINÕLES, C.; RUBIANES E. Origin of preovulatory follicles after induced luteolysis during the early luteal phase in ewes. Journal Animal Science, v. 51, p. 1351-1361, 1998.

YILDIZ, S.; SAATCI, M.; UZUN, M.; GUVEN, B. Effects of ram introduction after the second prostaglandin F2 $\alpha$ injection on day 11 on the LH surge characteristics in fat-tailed ewes, Reproduction Domestic Animal, v. 38, p. 54-57, 2003.

WHITE, I. R; RUSSEL, A.J.F; Body condition scoring in sheep. Practice, v. 6, p. 200, 1984. Censo Agropecuário 2006. Disponível em: <www.ibge.org.br.> Acesso em: 8 fev. 2008. 